\title{
Enhancement of Surfactin yield by improving the medium composition and fermentation process
}

\author{
Judit Willenbacher ${ }^{\text {** }}$ Wladimir Yeremchuk ${ }^{1}$, Teresa Mohr ${ }^{1}$, Christoph Syldatk and Rudolf Hausmann²
}

\begin{abstract}
Surfactin is one of the most promising biosurfactants due to its extraordinary surface activity. Commonly, the wellestablished Cooper medium, a glucose-based mineral salt medium, is utilized for the microbial production of Surfactin. The current study investigated the enhancement of Surfactin yields by analyzing the effects of different glucose concentrations, next to the introduction of an alternative chelating agent and nitrogen source. The utilization of $8 \mathrm{~g} / \mathrm{L}$ glucose, $0.008 \mathrm{mM} \mathrm{Na}_{3}$ citrate and $50 \mathrm{mM}\left(\mathrm{NH}_{4}\right)_{2} \mathrm{SO}_{4}$ increased Surfactin yields from 0.7 to $1.1 \mathrm{~g} / \mathrm{L}$ during shake flask experiments applying Bacillus subtilis $\mathrm{DSM}^{\top} \mathrm{O}^{\top}$. Consequentially conducted shake flask experiments, employing five other Surfactin producer strains during cultivation in the former and enhanced version of the Cooper medium, suggest a general enhancement of Surfactin yields during application of the enhanced version of the Cooper medium. The enhancement of the medium composition is therefore most likely independent from the employed producer strain. The following utilization of the enhanced medium composition during fed-batch fermentation with integrated foam fractionation yielded $30 \%$ more Surfactin in comparison to batch fermentations with integrated foam fractionation employing the former version of the Cooper medium.
\end{abstract}

Keywords: Surfactin, Medium, Glucose, Bacillus subtilis, Fermentation, Fed-batch

\section{Introduction}

Research focusing on the microbial production of surfactants increasingly gains attention due to the strong surface activity and specific characteristics of some of these biosurfactants (Banat et al. 2010). Surfactin is one of the most highly discussed microbial surfactants as it exhibits a very low critical micelle concentration $(0.036 \mathrm{~g} / \mathrm{L}$; Hirata et al. 2009) and lowers the surface tension of water to $27 \mathrm{mN} / \mathrm{m}$ (Arima et al. 1968). The lipopeptide consist of a peptide ring, comprising seven amino acids, and a $\beta$-hydroxy fatty acid. Many different characteristics of Surfactin are described, such as antitumor or antiviral activities (Kameda et al. 1974; Vollenbroich et al. 1997) but also induction of plants persistence against phytopathogens (Ongena and Jacques 2008) and

\footnotetext{
*Correspondence: judit.willenbacher@kit.edu

${ }^{1}$ Institute of Process Engineering in Life Sciences, Section II: Technical Biology, Karlsruhe Institute of Technology (KIT), Engler-Bunte-Ring 1, 76131 Karlsruhe, Germany

Full list of author information is available at the end of the article
}

insecticidal activity (Assié et al. 2002). Consequentially, there is a large number of possible applications of Surfactin e.g., in pharmaceuticals, agriculture, cosmetics, food industry or as a detergent.

Mostly the production of secondary metabolites in microorganisms is strongly influenced by the composition of the nutrients in their environment. Therefore, investigating a specific medium, with the aim to produce a certain molecule, usually becomes a highly discussed topic in its field of research. This also applies to the production of Surfactin with B. subtilis. Numerous suchlike studies, concerning the optimized medium or employing innovative carbon sources for the production of Surfactin, have been published (Peypoux et al. 1999). However, the typically utilized medium still demands further optimization as it does not comply with industrial standards, due to environmentally harmful components and substrate waste.

The shake flask experiments of Arima et al. (1968) using B. subtilis IAM 1213 were the benchmark for

\section{Springer}


Surfactin production until the early $1980 \mathrm{~s}(0.1 \mathrm{~g} / \mathrm{L})$. The Canadian group of Cooper et al. were the first to introduce an enhanced method for the production of Surfactin (Cooper et al. 1981), applying a foam fractionation process in a bioreactor but also introducing the first mineral salt medium for the production of Surfactin. The enhanced method led to a yield of $0.8 \mathrm{~g} / \mathrm{L}$ Surfactin. Although some research groups used the semisynthetic "Landy medium" (20 g/L glucose, $0.1 \%$ yeast extract; Nakano et al. 1988; Sandrin et al. 1990) the presented mineral salt medium, shortly after its introduction referred to as the "Cooper medium", became the basis for most of the employed media to produce Surfactin until today (Horowitz et al. 1990; Qiu et al. 2014; Yakimov et al. 1995).

During the last 15 years, sustainable resources, especially for use in biotechnological processes, became more and more important. This is based on the aim to combine innovative, microbially produced products with sustainable industrial processes. From this perspective many research groups focused on alternative carbon sources for the production of Surfactin instead of using glucose, as suggested in the Cooper medium. Possible alternative substrates were rice straw and soybean flour, potato process effluent, cashew apple juice, rehydrated whey powder, cassava flour or peat hydrolysate (CagriMehmetoglu et al. 2012; Davison et al. 2005; Freitas de Oliveira et al. 2013; Nitschke and Pastore 2004; Sheppard and Mulligan 1987; Zhu et al. 2013), all retaining low to moderate Surfactin yields $(0.29-3.0 \mathrm{~g} / \mathrm{L})$. However, most studies did not further analyze the improvement of Surfactin production by calculating essential process values like substrate utilization $\left(\mathrm{Y}_{\mathrm{X} / \mathrm{S}}, \mathrm{Y}_{\mathrm{P} / \mathrm{S}}\right)$ or specific $\left(\mathrm{q}_{\text {Surfactin }}\right)$ and overall product yields $\left(\mathrm{Y}_{\mathrm{P} / \mathrm{X}}\right)$. Other investigations focused on the productivity in respect of different sugars as carbon sources, proving glucose as the most effective (Abushady et al. 2005; Ghribi and Ellouze-Chaabouni 2011). On basis of these findings several studies investigated the optimal glucose concentration in mineral salt medium for the production of Surfactin or lichenysin with B. subtilis and B. licheniformis, respectively (Ghribi and Ellouze-Chaabouni 2011; Qiu et al. 2014; Sen 1997).

Sen (1997) analyzed the influence of glucose, $\mathrm{NH}_{4} \mathrm{NO}_{3}$, $\mathrm{FeSO}_{4}$ and $\mathrm{MnSO}_{4}$ in the Cooper medium on the production of Surfactin. The study was based on a $2^{4}$ full factorial central composite experimental design, allowing the analysis of four different parameters at the same time. The final result revealed $36.5 \mathrm{~g} / \mathrm{L}$ glucose, $5 \mathrm{~g} / \mathrm{L} \mathrm{NH}_{4} \mathrm{NO}_{3}$, $4 \times 10^{-3} \mathrm{~g} / \mathrm{L} \mathrm{FeSO}_{4}$ and $27.5 \times 10^{-2} \mathrm{~g} / \mathrm{L} \mathrm{MnSO}_{4}$ as the optimized medium composition. In contrast, the study of Ghribi and Ellouze-Chaabouni (2011) investigated seven different glucose concentrations from 15 to $45 \mathrm{~g} / \mathrm{L}$ in mineral salt medium and discovered $40 \mathrm{~g} / \mathrm{L}$ glucose as the improved carbon source for Surfactin production with $B$. subtilis SPB1. The maximum yield was $0.72 \mathrm{~g} / \mathrm{L}$ Surfactin. In contrast, a recent study (Qiu et al. 2014) investigated optimized glucose, $\mathrm{NH}_{4} \mathrm{NO}_{3}$ and buffer concentrations for the production of lichenysin. Five different glucose concentrations were analyzed from 10 to $50 \mathrm{~g} / \mathrm{L}$, where $30 \mathrm{~g} / \mathrm{L}$ was identified as the improved glucose concentration.

Although several studies on enhanced glucose concentrations for the production of Surfactin have been conducted, there is no conclusive explanation why high glucose concentrations are required in mineral salt medium. In this sense further experiments were realized with the aim to optimize the Surfactin production. Further obstacles of the previously applied medium were the nitrogen source $\mathrm{NH}_{4} \mathrm{Cl}$, which leads to an unnecessary accumulation of $\mathrm{NaCl}$ during $\mathrm{pH}$ control with $\mathrm{NaOH}$, and the chelating agent EDTA, which is detrimental to the environment (Oviedo and Rodríguez 2003). As a consequence, experiments were conducted to analyze alternative substrates for the substitution of $\mathrm{NH}_{4} \mathrm{Cl}$ and EDTA. In summary, the aim of this study was to enhance the Surfactin yield by changing the medium composition and to prove a general production enhancement independent from the applied Surfactin producer strain by changing the medium composition.

\section{Materials and methods}

\section{Microorganisms}

The wild type strain Bacillus subtilis DSM $10^{\mathrm{T}}$ was used in most experiments during the current study. A general enhancement of Surfactin productivity was tested employing the following Bacillus strains: DSM 3256, DSM 3258, DSM 1090, DSM 28227 and ATCC 21332. All microorganisms were obtained from the DSMZ (Deutsche Sammlung von Mikroorganismen und Zellkulturen $\mathrm{GmbH}$, Braunschweig, Germany) or ATCC (American Type Culture Collection, Manassas, Virginia, USA).

\section{Culture conditions \\ Media}

An overview about the different media used during this and previous studies is given in Table 1 (Cooper medium: A; slightly changed Cooper medium: B; enhanced medium: C). Stock solutions were used to assembly different medium combinations. The following final concentrations were adjusted every time: $0.03 \mathrm{M} \mathrm{KH}_{2} \mathrm{PO}_{4}$, $0.04 \mathrm{Na}_{2} \mathrm{HPO}_{4}, 0.0008 \mathrm{M} \mathrm{MgSO}, 0.007 \mathrm{mM} \mathrm{CaCl}$, $0.004 \mathrm{mM} \mathrm{FeSO}_{4}, 0.001 \mathrm{mM} \mathrm{MnSO}$. This implies that the buffer and trace element composition basically did not change throughout the experiments. In contrast, final concentrations of glucose varied widely $(0,2,4,6,8,10$, $12,15,20,30,40,50 \mathrm{~g} / \mathrm{L})$. Additionally, the substitution 
Table 1 Different media for the production of Surfactin with Bacillus subtilis

\begin{tabular}{|c|c|c|c|}
\hline & $\begin{array}{l}\text { Cooper } \\
\text { medium } \\
\text { A }\end{array}$ & $\begin{array}{l}\text { Modified } \\
\text { after Cooper } \\
\text { B }\end{array}$ & $\begin{array}{l}\text { Further } \\
\text { optimized } \\
\text { C }\end{array}$ \\
\hline C & $40 \mathrm{~g} / \mathrm{L}$ glucose & $40 \mathrm{~g} / \mathrm{L}$ glucose & $8 \mathrm{~g} / \mathrm{L}$ glucose \\
\hline N & $50 \mathrm{mM} \mathrm{NH}_{4} \mathrm{NO}_{3}$ & $100 \mathrm{mM} \mathrm{NH}_{4} \mathrm{Cl}$ & $50 \mathrm{mM}\left(\mathrm{NH}_{4}\right)_{2} \mathrm{SO}_{4}$ \\
\hline $\mathrm{Mg}$ & $0.8 \mathrm{mM} \mathrm{MgSO}_{4}$ & $0.8 \mathrm{mM} \mathrm{MgSO}_{4}$ & $0.8 \mathrm{mM} \mathrm{MgSO}_{4}$ \\
\hline Buffer & $\begin{array}{l}30 \mathrm{mM} \mathrm{KH}_{2} \mathrm{PO}_{4} \\
40 \mathrm{mM} \mathrm{Na}_{2} \mathrm{HPO}_{4}\end{array}$ & $\begin{array}{l}30 \mathrm{mM} \mathrm{KH}_{2} \mathrm{PO}_{4} \\
40 \mathrm{mM} \mathrm{Na}_{2} \mathrm{HPO}_{4}\end{array}$ & $\begin{array}{l}30 \mathrm{mM} \mathrm{KH}_{2} \mathrm{PO}_{4} \\
40 \mathrm{mM} \mathrm{Na}_{2} \mathrm{HPO}_{4}\end{array}$ \\
\hline \multirow[t]{4}{*}{$\begin{array}{l}\text { Trace } \\
\text { elements }\end{array}$} & $\begin{array}{c}0.004 \mathrm{mM} \\
\mathrm{Na}_{2} \text { EDTA }\end{array}$ & $\begin{array}{c}0.004 \mathrm{mM} \\
\mathrm{Na}_{2} \text { EDTA }\end{array}$ & $\begin{array}{l}0.008 \mathrm{mM} \mathrm{Na}_{3} \mathrm{Ci}- \\
\text { trate }\end{array}$ \\
\hline & $0.007 \mathrm{mM} \mathrm{CaCl}_{2}$ & $0.007 \mathrm{mM} \mathrm{CaCl}_{2}$ & $0.007 \mathrm{mM} \mathrm{CaCl}_{2}$ \\
\hline & $0.004 \mathrm{mM} \mathrm{FeSO}_{4}$ & $0.004 \mathrm{mM} \mathrm{FeSO}_{4}$ & $0.004 \mathrm{mM} \mathrm{FeSO}_{4}$ \\
\hline & $0.001 \mathrm{mM} \mathrm{MnSO}_{4}$ & $0.001 \mathrm{mM} \mathrm{MnSO}_{4}$ & $0.001 \mathrm{mM} \mathrm{MnSO}_{4}$ \\
\hline
\end{tabular}

The original medium after Cooper et al. is shown in the first column (A). A slightly changed version of this medium was used throughout most experiments for previous studies (B). Hereby, the nitrogen source $\mathrm{NH}_{4} \mathrm{NO}_{3}$ was replaced by $\mathrm{NH}_{4} \mathrm{Cl}$. During the current study the medium was further optimized to yield more Surfactin (C), employing less glucose $(8 \mathrm{~g} / \mathrm{L}),\left(\mathrm{NH}_{4}\right)_{2} \mathrm{SO}_{4}$ and $\mathrm{Na}_{3}$ citrate

of $\mathrm{NH}_{4} \mathrm{Cl}\left(0.1 \mathrm{M}\right.$; medium B) by $\left(\mathrm{NH}_{4}\right)_{2} \mathrm{SO}_{4}(0.05 \mathrm{M}$; medium $\mathrm{C})$ and the replacement of $\mathrm{Na}_{2}$ EDTA $(0.004 \mathrm{mM}$, medium B) with $\mathrm{Na}_{3}$ citrate $(0.008 \mathrm{mM}$, medium $\mathrm{C})$ was performed to investigate a novel nitrogen source and chelating agent, respectively.

Fermentations were carried out with the final version of the optimized medium (Table 1: medium C). Stock solutions for the preparation of the bioreactor medium were prepared as described in Willenbacher et al. (2014), except for the concentration of the glucose stock solution which was about $48 \mathrm{~g} / \mathrm{L}$ in $250 \mathrm{~mL}$ and the usage of $0.05 \mathrm{M}\left(\mathrm{NH}_{4}\right)_{2} \mathrm{SO}_{4}$ and $0.008 \mathrm{mM} \mathrm{Na}_{3}$ citrate. In contrast, to medium $\mathrm{B}$ (Table 1), medium $\mathrm{C}$ was limited by the amount of glucose. In order to cultivate for a similar amount of time, compared to cultivations in Willenbacher et al. (2014) (approximately $30 \mathrm{~h}$ ), glucose was additionally fed to extend the cultivation time (from $20.83 \mathrm{~h}$ to $34 \mathrm{~h}$ ). Therefore, a stock solution of $450 \mathrm{~g} / \mathrm{L}$ glucose was prepared $(23 \mathrm{~mL})$ for inoculation after complete glucose consumption.

\section{Preparation of inoculum cultures}

The precultures were incubated for $24 \mathrm{~h}$ at $30{ }^{\circ} \mathrm{C}$ and $120 \mathrm{rpm}$ in a shake incubator chamber (Multitron II, HT Infors, Bottmingen, Switzerland). The 20 or $100 \mathrm{~mL}$ mineral salt medium for main culture (in 100 and $500 \mathrm{~mL}$ baffled shake flasks, respectively) were inoculated with a resulting $\mathrm{OD}_{600}$ between 0.05 and 0.1 .

Two consecutive precultures were prepared for cultivations in benchtop bioreactors. The $500 \mathrm{~mL}$ baffled shake flasks, containing $100 \mathrm{~mL}$ of medium $\mathrm{C}$, were inoculated to a resulting $\mathrm{OD}_{600}$ of 0.1 . The benchtop bioreactors were inoculated from the second preculture to a resulting $\mathrm{OD}_{600}$ of 0.1 .

\section{Shake flask cultivations}

Cultivations in shake flasks were conducted to investigate different medium compositions and to analyze the Surfactin production of different Bacillus strains in medium $B$ and medium $C$ (Table 1). All shake flask experiments were performed as duplicates. In some cases the flasks were inoculated in a time-displaced way to collect samples of all cultivation phases. The cultivation duration varied between 30 and $50 \mathrm{~h}$. Samples were taken by day every $2-3 \mathrm{~h}$. The cultivation was stopped if the measured $\mathrm{OD}_{600}$ decreased after a significant growth phase.

\section{Cultivation in a $2.5 \mathrm{~L}$ benchtop bioreactor}

Bioreactor cultivations were carried out as described in Willenbacher et al. (2014), using the same benchtop bioreactor system with $\mathrm{pH}, \mathrm{pO}_{2}$ and temperature control (Minifors, HT Infors, Bottmingen, Switzerland). Since foam fractionation was applied, the foam was channeled through the exhaust cooler and collected in interchangeable bags. In contrast to Willenbacher et al. (2014), fermentations were conducted as fed-batch cultivations. After the depletion of glucose, the level of dissolved oxygen dramatically increased (because the cells suddenly experienced starvation). At this point a glucose stock solution was injected to increase the level of glucose in the bioreactor to the starting glucose concentration of approximately $8 \mathrm{~g} / \mathrm{L}$. As a result, the cultivation time was extended for $13.17 \mathrm{~h}$. Samples were taken every $2 \mathrm{~h}$ accompanied by the exchange of the foam trap against a new collecting bag (applies only if foam was already leaving the bioreactor). All fermentations were performed as duplicates.

\section{Analytical methods \\ Sampling and sample processing}

The samples taken during shake flask experiments were analyzed regarding $\mathrm{OD}_{600}$ (later on converted into cell dry weight (CDW) by division with the correlation factor 3; in case of B. subtilis DSM 3258 the pelleted growth prevented the determination of $\mathrm{OD}_{600}$ absorption) and Surfactin concentration (HPLC). The samples taken from the bioreactor were as well analyzed in respect of their $\mathrm{OD}_{600}$ (later indicated as CDW) and Surfactin concentration, but furthermore for their glucose concentration (enzymatic assay). Samples of the foam traps were also analyzed regarding their CDW, Surfactin and glucose concentration. The employed methods to quantify $\mathrm{OD}_{600}$, glucose, and Surfactin concentration were equivalent to the methods described in Willenbacher et al. (2014). 


\section{Data analysis}

An analysis of different process parameters allowed the evaluation of the applied fermentation process (fedbatch, Table 1: medium C) with earlier findings from cultivations in the original medium (batch, Table 1: medium B). Using the results of CDW, mass of glucose and mass of Surfactin, the values of $\mathrm{Y}_{\mathrm{X} / \mathrm{S}}[\mathrm{g} / \mathrm{g}], \mathrm{Y}_{\mathrm{P} / \mathrm{X}}[\mathrm{g} / \mathrm{g}], \mathrm{Y}_{\mathrm{P} / \mathrm{S}}[\mathrm{g} / \mathrm{g}]$, $\mu\left[\mathrm{h}^{-1}\right], \mathrm{q}_{\text {Surfactin }}[\mathrm{g} /(\mathrm{g} \mathrm{h})]$, volumetric $\mathrm{q}_{\text {Surfactin }}[\mathrm{g} /(\mathrm{L} \mathrm{h})]$, Surfactin recovery [\%], Surfactin enrichment and bacterial enrichment were determined as described in Willenbacher et al. (2014).

\section{Results}

Improvement of the copper medium to enhance Surfactin yields

The original Cooper medium (Cooper et al. 1981; Table 1: medium A) presents glucose as carbon source and $\mathrm{NH}_{4} \mathrm{NO}_{3}$ as nitrogen source. The buffer system is composed of $\mathrm{KH}_{2} \mathrm{PO}_{4}$ and $\mathrm{Na}_{2} \mathrm{HPO}_{4}$. Aside from that, the addition of $\mathrm{MgSO}_{4}$ serves as source for sulfur and magnesium. Additionally, the trace elements $\mathrm{Fe}, \mathrm{Ca}$ and $\mathrm{Mn}$ are added together with the chelating agent EDTA. Early experiments contributing to previous studies (Willenbacher et al. 2014) were conducted with a slightly modified version of the Cooper medium (Table 1: medium B). The nitrogen source $50 \mathrm{mM} \mathrm{NH} \mathrm{NH}_{3}$ was exchanged against $1 \mathrm{M} \mathrm{NH}_{4} \mathrm{Cl}$ mainly because Bacillus prefers $\mathrm{NH}_{4}$ over $\mathrm{NO}_{3}$ as nitrogen source. Furthermore, the employment of $\mathrm{NH}_{4} \mathrm{Cl}$ solely required the analysis of one nitrogen compound. Additionally, the original $70 \mathrm{mM}$ buffer system was replaced by a $10 \mathrm{mM}$ buffer system when $B$. subtilis was cultivated in a benchtop bioreactor allowing $\mathrm{pH}$ control. In this way, it was possible to monitor the bacterial growth by the online acquisition of $\mathrm{NaOH}$ addition. The original glucose concentration was not altered, since earlier studies suggested $40 \mathrm{~g} / \mathrm{L}$ as the optimal glucose concentration (Ghribi and Ellouze-Chaabouni 2011; Sen 1997).

Although repeatedly reliable results were obtained while employing the slightly changed Cooper medium (Table 1: medium B) this medium composition was further investigated to avoid unnecessary environmentally harmful components and substrate waste. As a consequence the chelating agent EDTA was replaced by citrate, which is a much more environmentally friendly and more favorable chelating agent. Furthermore, the nitrogen source $\mathrm{NH}_{4} \mathrm{Cl}$ was substituted by $\left(\mathrm{NH}_{4}\right)_{2} \mathrm{SO}_{4}$, which prevents the accumulation of $\mathrm{NaCl}$ (caused by the addition of $\mathrm{NaOH}$ for $\mathrm{pH}$ control) inside the bioreactor and increases the amount of sulfur (which is comparably low in the original Cooper medium). Both substitutions did not affect bacterial growth or Surfactin productivity (data not shown).

The first shake flask cultivations revealed a higher Surfactin concentration at cultivations employing lower glucose concentrations. Subsequently, a shake flask experiment applying 0, 2, 4, 6, 8, 10, 12 and 15 g/L glucose was conducted encircling the improved glucose concentration for the production of Surfactin with B. subtilis DSM $10^{\mathrm{T}}$ (the results of CDW and Surfactin yields are shown in the appendix, Additional file 1: Figure S1). The highest Surfactin yields were reached applying 6 and $8 \mathrm{~g} / \mathrm{L}$ glucose (approximately $0.8 \mathrm{~g} / \mathrm{L}$ Surfactin). These results surpassed Surfactin yields from shake flask cultivations employing the original $40 \mathrm{~g} / \mathrm{L}$ glucose $(0.6 \mathrm{~g} / \mathrm{L}$ Surfactin).

Figure 1 compares the results of the former applied medium (slightly changed Cooper medium, Table 1: medium B) and the finally enhanced medium (Table 1: medium $C$ ). Time courses of the simultaneous cultivations of B. subtilis DSM $10^{\mathrm{T}}$ in the two different media reveal a maximal $\mathrm{CDW}$ of $2.4 \mathrm{~g} / \mathrm{L}$ in medium $\mathrm{B}$ and
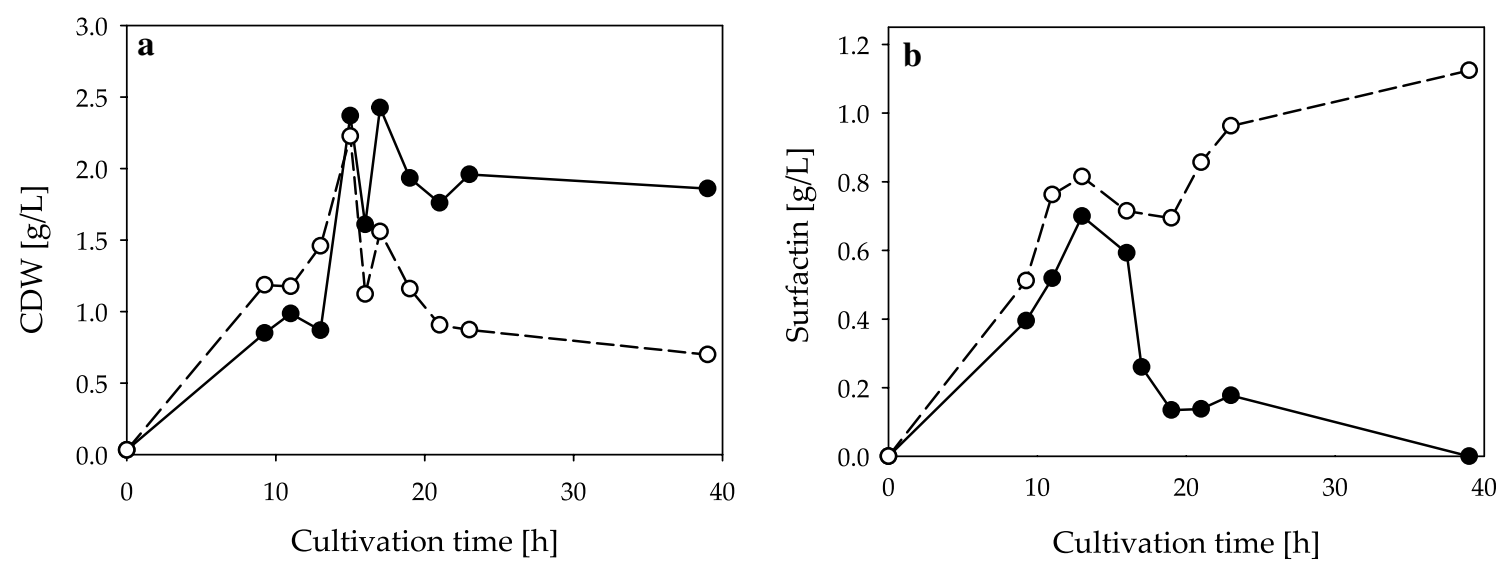

Fig. 1 Time course of CDW and Surfactin concentrations of B. subtilis DSM $10^{\top}$ during shake flask cultivations in medium B and further optimized medium C. The achieved CDW $[\mathrm{g} / \mathrm{L}]$ is shown in $\mathbf{a}$, whereas resulting Surfactin concentrations $[\mathrm{g} / \mathrm{L}]$ are illustrated in $\mathbf{b}$. The results of cultivation in medium $B$ are given as black dots. Data from cultivations in medium $C$ are presented as white dots. The cultivations were conducted as duplicates and in time-displaced flasks to illustrate a continuous course of growth and Surfactin production 
$2.2 \mathrm{~g} / \mathrm{L}$ in medium C. Bacterial growth terminated after $15 \mathrm{~h}$ of cultivation in medium $\mathrm{C}$ as the further optimized medium is glucose limited. Nevertheless, a significantly higher concentration of Surfactin was produced in the further optimized medium $\mathrm{C}$, yielding a maximum of $1.1 \mathrm{~g} / \mathrm{L}$ Surfactin. In contrast, cultivations in medium B reached $0.7 \mathrm{~g} / \mathrm{L}$ as maximal Surfactin concentration. This comparison shows a significant enhancement in Surfactin yields after medium optimization during shake flask cultivations.

\section{Does the optimized Cooper medium enhance Surfactin production in general?}

To investigate whether the improved Surfactin yields during cultivation in the enhanced Cooper medium (Table 1: medium C) depend on the employed Bacillus strain DSM $10^{\mathrm{T}}$, further shake flask experiments were conducted to analyze the Surfactin productivity of several other Bacillus strains in the optimized medium C.

The B. subtilis strains DSM $10^{\mathrm{T}}$, DSM 28227, ATCC 21332, DSM 3256, DSM 1090 and DSM 3258 were analyzed regarding their Surfactin production during cultivation in medium B and medium C (Table 1). The CDW and Surfactin concentrations of these cultivations are shown in the appendix in Additional file 1: Figure S2. Most interestingly, the production of Surfactin seems to be enhanced in all cultivations employing the optimized medium C. Except for the results of DSM 3258, where the Surfactin production increased during cultivation in medium B. However, Surfactin production was generally very low $(0.05-0.1 \mathrm{~g} / \mathrm{L})$ during the cultivations of DSM 3258 and the shown error bars indicate a rather similar production rate during cultivation in medium $B$ and C. In summary, the concentration of Surfactin was doubled to tripled during cultivation of DSM $10^{\mathrm{T}}$, DSM 28227, ATCC 21332, DSM 3256 and DSM 1090 employing the enhanced medium $C$ in comparison to the previously applied medium B (sole exception DSM 3258), which suggests a general improvement of Surfactin production during cultivation in medium $\mathrm{C}$ independent from the applied Bacillus strain.

\section{Discussion}

\section{Comparison with other studies analyzing the medium composition}

As described earlier, Sen (1997) applied a design of experiment approach to analyze the influence of the medium components concentrations. In this fashion, solely three different concentrations were tested without altering the other three variables $\left(\mathrm{NH}_{4} \mathrm{NO}_{3}, \mathrm{FeSO}_{4}\right.$ and $\mathrm{MnSO}_{4}$ ). In the case of glucose, three shake flask experiments were conducted with 0,40 and $80 \mathrm{~g} / \mathrm{L}$ glucose without changing the other medium components. This is a normal and common strategy when a design of experiment is approached, but covers a rather unrealistic range of glucose concentrations. Consequentially, shake flask cultivations containing no carbon source will not yield any Surfactin as cells are not able to grow properly. Furthermore, cultivations employing $80 \mathrm{~g} / \mathrm{L}$ glucose should also be expected to yield low Surfactin concentrations as excess glucose concentrations negatively affect the growth behavior of B. subtilis (Dauner et al. 2001). The consequence is a much higher yield of Surfactin in cultivations with $40 \mathrm{~g} / \mathrm{L}$ glucose. Consequently, $36.5 \mathrm{~g} / \mathrm{L}$ was found to be the optimized glucose concentration.

Another important reference point is the applied method for the analysis of Surfactin yield. Sen (1997) determined the Surfactin yield via an indirect method measuring the surface tension. The relative Surfactin concentration was defined by serially diluting the culture broth until the critical micelle concentration (CMC) was reached. The number of dilutions which was necessary to start rising the surface tension was designated as $\mathrm{CMC}^{-1}$. Such indirect methods can be used to achieve a certain indication, but do not give specific information about the actual amount of product as the surface tension could be lowered by several other surfactants produced by Bacillus (e.g. Iturin or Fengycin).

The study of Ghribi and Ellouze-Chaabouni (2011) determined the Surfactin concentrations by approaching an indirect method as well. There, the precipitated and extracted crude product was weighed. This study identified $40 \mathrm{~g} / \mathrm{L}$ as the most suitable glucose concentration as it yielded $0.72 \mathrm{~g} / \mathrm{L}$ Surfactin. The determination of the Surfactin yield in this fashion is rather difficult, as shake flask experiments do not supply much product and during precipitation and extraction with chloroform and methanol lots of product is lost. Moreover, the precipitation with $\mathrm{HCl}$ (until reaching $\mathrm{pH}=2.0)$ and following extraction with organic solvents does not necessarily lead to pure product.

In contrast, Qiu et al. (2014) applied HPLC to quantify the amount of produced lichenysin $(1.25 \mathrm{~g} / \mathrm{L}$ lichenysin with $30 \mathrm{~g} / \mathrm{L}$ glucose in mineral salt medium). HPLC is the most accurate detection method, as the product is specifically identified by several peaks at characteristic retention times. Inevitable here is the application of a pure standard (e.g. Surfactin from Sigma-Aldrich). Qiu et al. (2014) were not able to purchase a lichenysin standard and therefore used Surfactin as a reference. Both lichenysin and Surfactin produce various isoforms, since different amino acids and fatty acids can be incorporated. It is therefore not very accurate to use Surfactin as HPLC standard for the detection of lichenysin. However, lichenysin was not commercially available at the time, hence Qiu et al. (2014) determined the lichenysin concentration as exactly as possible. Qiu et al. (2014) 
determined the product yield in the most accurate way in comparison to the other consulted studies. Nevertheless, the study identified $30 \mathrm{~g} / \mathrm{L}$ glucose as the improved concentration for maximal product yield. The discrepancy between the results of the current study $(8 \mathrm{~g} / \mathrm{L}$ glucose as optimized concentration in the medium) and the study of Qiu et al. (2014; 30 g/L glucose) might be explained by the usage of two different strains (Bacillus subtilis and Bacillus licheniformis) and could also be referred to different regulation and expression of the $\operatorname{srf} A$ and $l \operatorname{ch} A$ operons (the upstream region of the two operons seem to be similar but not identical, Sen 2010).

The results of Sen (1997), Ghribi and EllouzeChaabouni (2011) and Qiu et al. (2014) conflict the results of this study, which suggest $8 \mathrm{~g} / \mathrm{L}$ glucose as enhanced concentration. The discrepancy could be explained by the fashion in which the experiments were conducted. All of the above studies focused either on glucose concentrations between $10 \mathrm{~g} / \mathrm{L}$ and $50 \mathrm{~g} / \mathrm{L}$ or used unsuitable low or high glucose concentrations (Sen, 1997). None of these studies incorporated experiments with $8 \mathrm{~g} / \mathrm{L}$ glucose. Another reason could be the manner in which samples were taken. All of the discussed studies analyzed the Surfactin or lichenysin concentration at the end of cultivation. However, the product yield fluctuates greatly during the cultivation, which means maximal concentrations may have been missed. Additionally, detection methods (especially in the studies of Sen and Ghribi and Ellouze-Chaabouni) for the analysis of Surfactin lack specificity. Multiple applications of the optimized Cooper medium (Table 1: medium $\mathrm{C}$ ) during cultivations of B. subtilis DSM $10^{\mathrm{T}}$ and additional cultivations of further Surfactin producers in the current study proved a consistent enhancement of Surfactin yield. Therefore the following experiments were conducted in the improved medium $\mathrm{C}$.

\section{Application of the optimized Cooper medium during cultivation in a $2.5 \mathrm{~L}$ benchtop bioreactor with integrated foam fractionation}

The shake flask cultivations of $B$. subtilis DSM $10^{\mathrm{T}}$ using the optimized medium (Table 1: medium $C$ ) reached significantly higher values for the production of Surfactin compared to results employing the former medium (Table 1: medium B). The results of the bioreactor cultivation of $B$. subtilis DSM $10^{\mathrm{T}}$ applying foam fractionation in medium B (presented in Willenbacher et al. 2014) were already promising concerning Surfactin recovery, enrichment and total mass of Surfactin. After the final optimization of the medium another bioreactor cultivation of $B$. subtilis DSM $10^{\mathrm{T}}$ with integrated foam fractionation was conducted to compare production rates of Surfactin with results obtained from cultivations presented in Willenbacher et al. (2014).

The bioreactor cultivations of Willenbacher et al. (2014) were performed as batch cultivations. As the optimized medium $\mathrm{C}$ is glucose limited batch cultivations would stop much earlier compared to cultivations with medium B. Therefore, a fed-batch cultivation was applied for the cultivation of B. subtilis DSM $10^{\mathrm{T}}$ in the optimized medium $C$. The fermentation plot is shown in Fig. 2. Fermentations endured for $34 \mathrm{~h}$ and yielded a

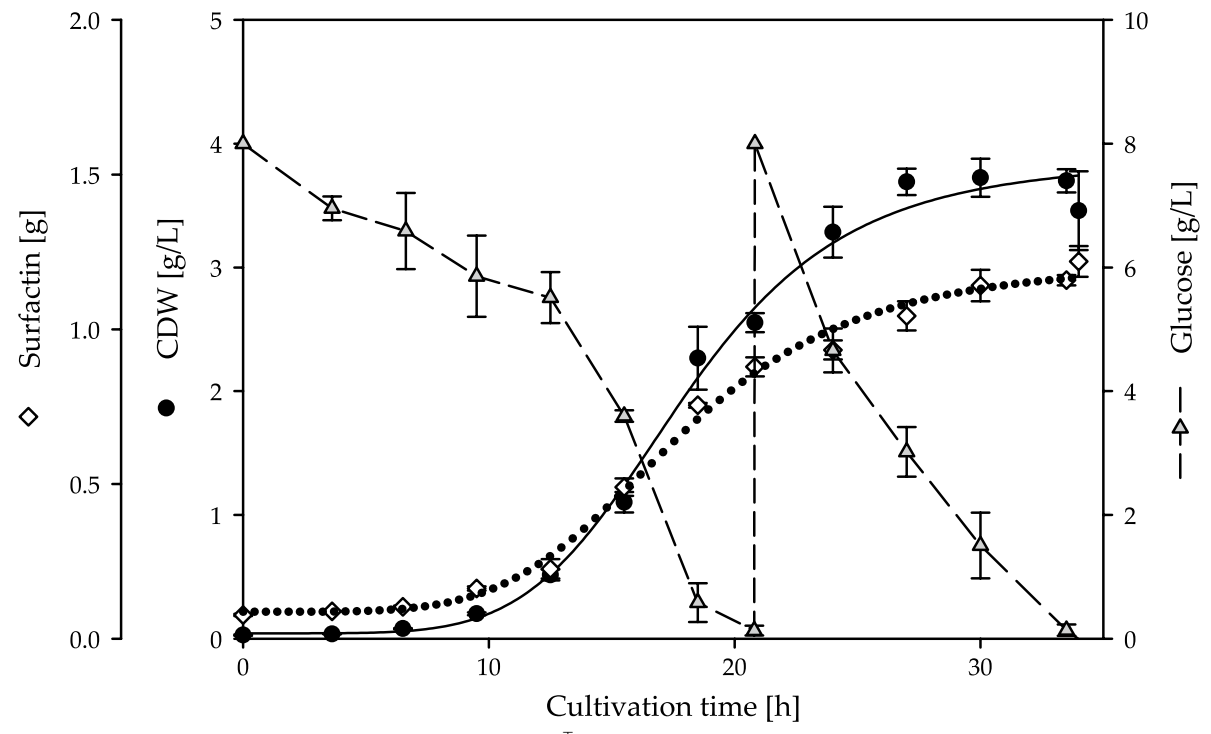

Fig. 2 Time course of the fed-batch fermentation of B. subtilis DSM $10^{\top}$ employing medium C. The time courses of CDW (black dot, [g/L]), Surfactin (white rhombus, [g]) and glucose (grey triangle, [g/L]) are displayed as mean values of two fermentations. Glucose was added after its complete consumption (23 mL of $450 \mathrm{~g} / \mathrm{L}$ glucose, $20.83 \mathrm{~h}$ after inoculation). The dotted and solid lines represent logistic fits of CDW and mass of Surfactin 
maximal CDW of $3.8 \mathrm{~g} / \mathrm{L}$. The decrease of glucose is visible until its complete depletion after $20.83 \mathrm{~h}$ of cultivation. Glucose was added to the culture broth to continue the cultivation ( $23 \mathrm{~mL} 450 \mathrm{~g} / \mathrm{L}$ glucose), resulting in a glucose concentration of $8 \mathrm{~g} / \mathrm{L}$. The amount of glucose inside the bioreactor decreased again until its consumption after $34 \mathrm{~h}$ of cultivation. The increase of CDW and Surfactin followed a logistic growth behavior during cultivations, yielding $1.22 \mathrm{~g}$ Surfactin. The analysis of the foam traps is shown in Fig. 3 (example of one bioreactor cultivation). The Surfactin recovery increased during cultivations from 52 to $88 \%$, whereas Surfactin (15-27) and bacterial enrichment (0.1-0.7) remained nearly constant.

An overview about the pre-post comparison of the media B and C (Table 1) is given in Table 2. Various process parameters are listed in comparison to emphasize the effects of the different media. The growth behavior of B. subtilis DSM $10^{\mathrm{T}}$ differed only slightly during employment of the optimized medium $C$. The value of $\mathrm{Y}_{\mathrm{X} / \mathrm{S}}$ decreased in comparison to the fermentation from Willenbacher et al. (2014) $\left(\mathrm{Y}_{\mathrm{X} / \mathrm{S}}=0.20 \mathrm{~g} / \mathrm{g}\right.$ in contrast to $\mathrm{Y}_{\mathrm{X} / \mathrm{S}}=0.27 \mathrm{~g} / \mathrm{g}$ ), but values for maximal growth rate $\mu$ and cultivation time remained on a similar level. However, the concentration of CDW increased significantly from 2.97 to $3.80 \mathrm{~g} / \mathrm{L}$ during cultivation with medium C. The analysis of the foam traps identified a considerable decline in Surfactin enrichment, where maximal values of 101.92 decreased to 27.10. The Surfactin recovery decreased as well during employment of medium $\mathrm{C}$ in comparison to fermentations applying medium $\mathrm{B}$
(83.81\% instead of $91.96 \%)$, although not as drastic as the Surfactin enrichment. In contrast, values for bacterial enrichment improved significantly with a mean value of 0.4 during application of medium $\mathrm{C}$ compared to the mean value during fermentations employing medium $B$ (1.60). The production rate increased significantly as values for $Y_{P / X}$ rose from $0.19 \mathrm{~g} / \mathrm{g}$ (batch, medium $B$ ) to $0.26 \mathrm{~g} / \mathrm{g}$ (fed-batch, medium C). Values for $\mathrm{Y}_{\mathrm{P} / \mathrm{S}}$ increased as well yielding $0.05 \mathrm{~g} / \mathrm{g}$ instead of $0.03 \mathrm{~g} / \mathrm{g}$. The specific production rates $\mathrm{q}_{\text {Surfactin }}$ and vol. $\mathrm{q}_{\text {Surfactin }}$ achieved values of $0.009 \mathrm{~g} /(\mathrm{g} \mathrm{h})$ and $0.022 \mathrm{~g} /(\mathrm{L} \mathrm{h})$ [batch, medium B: $\mathrm{q}_{\text {Surfactin }}=0.006 \mathrm{~g} /(\mathrm{g} \mathrm{h})$, vol. $\left.\mathrm{q}_{\text {Surfactin }}=0.017 \mathrm{~g} /(\mathrm{L} \mathrm{h})\right]$. The improvement of the production rates becomes even more significant when analyzing the amount of produced Surfactin. The maximal Surfactin concentration in foam did not increase during cultivation employing medium $C$ (3.67 g/L Surfactin in comparison to $3.99 \mathrm{~g} / \mathrm{L}$ Surfactin applying medium $\mathrm{B}$ ), but the total foam volume leaving the bioreactor increased from $334 \mathrm{~mL}$ (batch, medium B) to $435 \mathrm{~mL}$ (fed-batch, medium C). The collected amount of Surfactin inside the foam traps added up to $1.02 \mathrm{~g}$ Surfactin in fermentations employing medium $\mathrm{C}$ in contrast to $0.74 \mathrm{~g}$ Surfactin in fermentations applying medium B. In total $1.22 \mathrm{~g}$ Surfactin was produced employing the optimized medium $\mathrm{C}$ and a fed-batch strategy in comparison to $0.81 \mathrm{~g}$ Surfactin during batch fermentations applying medium $\mathrm{B}$. This proves an enhancement of the Surfactin production of approximately $30 \%$ based on the conversion of the fermentation strategy and medium optimization.

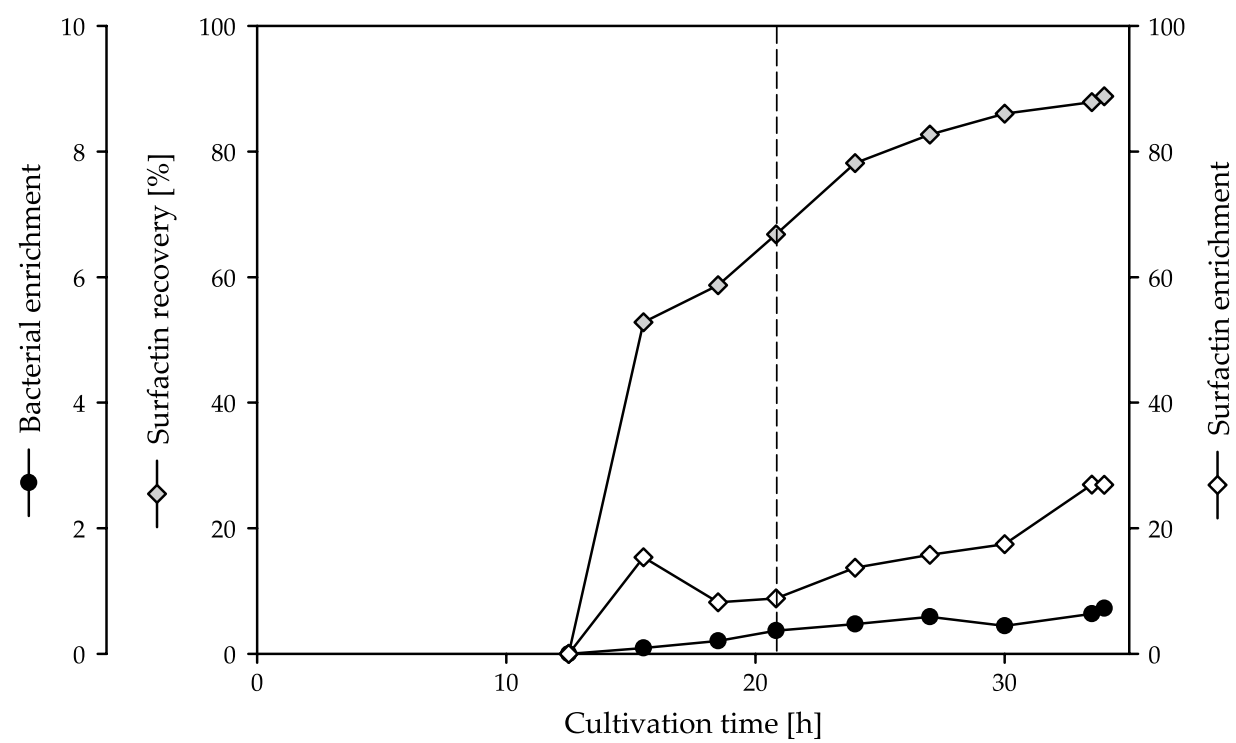

Fig. 3 Time course of foam traps during fed-batch fermentation of B. subtilis DSM $10^{\top}$ employing medium C. The values of bacterial enrichment (black dots), Surfactin recovery (grey rhombus) and Surfactin enrichment (white rhombus) are displayed as exemplary results of one fermentation. The addition of glucose is indicated by a dashed line after $20.83 \mathrm{~h}$ of cultivation 
Table 2 Comparison of process parameters during fermentation of Bacillus subtilis DSM $10^{\top}$ employing medium $B$ and $C$

\begin{tabular}{|c|c|c|}
\hline & $\begin{array}{l}\text { Fed-batch } \\
\text { The current study }\end{array}$ & $\begin{array}{l}\text { Batch } \\
\text { Willenbacher } \\
\text { et al. (2014) }\end{array}$ \\
\hline Applied medium & C & B \\
\hline Fermentation approach & Foam fractionation & Foam fractionation \\
\hline Initial glucose conc. & $8 \mathrm{~g} / \mathrm{L}$ & $40 \mathrm{~g} / \mathrm{L}$ \\
\hline Addition of glucose & $23 \mathrm{~mL}$ of $450 \mathrm{~g} / \mathrm{L}$ & - \\
\hline Final glucose conc. & $0 \mathrm{~g} / \mathrm{L}$ & $29.19 \mathrm{~g} / \mathrm{L}$ \\
\hline Cultivation time (h) & 34 & 30 \\
\hline Max. CDW (g/L) & 3.80 & 2.97 \\
\hline$\mu_{\max }\left(h^{-1}\right)$ & 0.31 & 0.34 \\
\hline 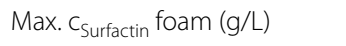 & 3.67 & 3.99 \\
\hline Foam volume $(\mathrm{mL})$ & 435 & 334 \\
\hline Surfactin in foam (g) & 1.02 & 0.74 \\
\hline Overall Surfactin (g) & 1.22 & 0.81 \\
\hline$Y_{P / X}(g / g)$ & 0.26 & 0.19 \\
\hline$Y_{X / S}(g / g)$ & 0.20 & 0.27 \\
\hline$Y_{P / S}(g / g)$ & 0.05 & 0.03 \\
\hline Int. Ssurfactin $\left._{\text {[g/(g h) }}\right]$ & 0.009 & 0.006 \\
\hline Int. vol. $q_{\text {Surfactin }}[\mathrm{g} /(\mathrm{L} h)]$ & 0.022 & 0.017 \\
\hline Overall Surfactin recovery (\%) & 83.81 & 91.96 \\
\hline Max. Surfactin enrichment & 27.10 & 101.92 \\
\hline Mean bacterial enrichment & 0.41 & 1.60 \\
\hline
\end{tabular}

The approach and results of $B$. subtilis DSM $10^{\top}$ batch fermentation

(Willenbacher et al. 2014) is compared to data collected during fed-batch

fermentation of B. subtilis DSM $10^{\top}$ employing the further optimized medium C

As a first conclusion it must be emphasized that Surfactin is not consistently produced throughout the cultivations. This has been taken into account during this study and it became possible to significantly enhance the Surfactin productivity for the strain B. subtilis DSM $10^{\mathrm{T}}$. The substitution of the medium components $\mathrm{NH}_{4} \mathrm{Cl}$ and EDTA with $\left(\mathrm{NH}_{4}\right)_{2} \mathrm{SO}_{4}$ and citrate, as well as the alteration of the glucose concentration (from 40 to $8 \mathrm{~g} / \mathrm{L}$ ) improved the production of Surfactin during shake flask experiments. Further shake flask cultivations revealed a general enhancement of Surfactin productivity independent from the employed Bacillus strains. The utilization of the improved medium would most likely also lead to better results for other B. subtilis strains. Comparable studies did not prefer low glucose concentrations, but failed to analyze concentrations below $10 \mathrm{~g} / \mathrm{L}$ glucose. The comparison of fermentations employing the optimized medium plus a fed-batch strategy and fermentations applying the original medium in a batch process (Willenbacher et al. 2014) revealed an enhancement of Surfactin production of approximately $30 \%$.

\section{Additional file}

Additional file 1. Shake flask cultivations analyzing different glucose concentrations and yield enhancement of other Surfactin producer strains.

\section{Authors' contributions}

JW collected and calculated all data, created the graphs and figures and drafted this manuscript. WY conducted his Master thesis under the supervision of JW and contributed the data of the first shake flask experiments and fermentations. TM conducted several shake flask experiments to evaluate the Surfactin productivity of different Bacillus strains. CS and RH substantially contributed to conception and design of the conducted experiments. All authors read and approved the final manuscript.

\section{Author details}

${ }^{1}$ Institute of Process Engineering in Life Sciences, Section II: Technical Biology, Karlsruhe Institute of Technology (KIT), Engler-Bunte-Ring 1, 76131 Karlsruhe, Germany. ${ }^{2}$ Institute of Food Science and Biotechnology (150), Section Bioprocess Engineering (150k), University of Hohenheim, Garbenstr. 25 70599 Stuttgart, Germany.

\section{Acknowledgements}

We acknowledge the support by Deutsche Forschungsgemeinschaft and Open Access Publishing Fund of Karlsruhe Institute of Technology.

Compliance with ethical guidelines

Competing interests

The authors declare that they have no competing interests.

Received: 13 May 2015 Accepted: 6 August 2015

Published online: 22 August 2015

\section{References}

Abushady H, Bashandy A, Aziz N, Ibrahim H (2005) Molecular characterization of Bacillus subtilis surfactin producing strain and the factors affecting its production. Int J Agr Biol 3:337-344

Arima K, Kakinuma A, Tamura G (1968) Surfactin, a crystalline peptidelipid surfactant produced by Bacillus subtilis: isolation, characterization and its inhibition of fibrin clot formation. Biochem Bioph Res Co 31:488-494

Assié LK, Deleu M, Arnaud L, Paquot M, Thonart P, Gaspar C, Haubruge E (2002) Insecticide activity of surfactins and iturins from a biopesticide Bacillus subtilis Cohn (S499 strain). Meded Rijksuniv Gent Fak Landbouwkd Toegep Biol Wet 67:647-655

Banat IM, Franzetti A, Gandolfi I, Bestetti G, Martinotti MG, Fracchia L, Smyth TJ, Marchant R (2010) Microbial biosurfactants production, applications and future potential. Appl Microbiol Biot 87:427-444

Cagri-Mehmetoglu A, Kusakli S, van de Venter M (2012) Production of polysaccharide and surfactin by Bacillus subtilis ATCC 6633 using rehydrated whey powder as the fermentation medium. J Dairy Sci 95:3643-3649

Cooper D, Macdonald C, Duff S, Kosaric N (1981) Enhanced production of surfactin from Bacillus subtilis by continuous product removal and metal cation additions. Appl Environ Microb 42:408-412

Dauner M, Storni T, Sauer U (2001) Bacillus subtilis metabolism and energetics in carbon-limited and excess-carbon chemostat culture. J Bacteriol 183:7308-7317

Davison B, Evans B, Finkelstein M, McMillan J, Noah K, Bruhn D, Bala G (2005) Surfactin production from potato process effluent by Bacillus subtilis in a chemostat. Appl Biochem Biotech 465-473. Humana Press

Freitas de Oliveira DW, Lima Franca IW, Nogueira Félix AK, Lima Martins JJ, Aparecida Giro ME, Melo VMM, Goncalves LRB (2013) Kinetic study of biosurfactant production by Bacillus subtilis LAMI005 grown in clarified cashew apple juice. Colloid Surf B 101:34-43 
Ghribi D, Ellouze-Chaabouni S (2011) Enhancement of Bacillus subtilis lipopeptide biosurfactants production through optimization of medium composition and adequate control of aeration. Biotechnol Res Int 2011:653654

Hirata Y, Ryu M, Oda Y, Igarashi K, Nagatsuka A, Furuta T, Sugiura M (2009) Novel characteristics of sophorolipids, yeast glycolipid biosurfactants, as biodegradable low-foaming surfactants. J Biosci Bioeng 108:142-146

Horowitz S, Gilbert JN, Griffin WM (1990) Isolation and characterization of a surfactant produced by Bacillus licheniformis 86. J Ind Microbiol $6: 243-248$

Kameda Y, Ouhira S, Matsui K, Kanatomo S, Hase T, Atsusaka T (1974) Antitumor activity of Bacillus natto. V. Isolation and characterization of surfactin in the culture medium of Bacillus natto KMD 2311. Chem Pharm Bull 22:938-944

Nakano MM, Marahiel M, Zuber P (1988) Identification of a genetic locus required for biosynthesis of the lipopeptide antibiotic surfactin in Bacillus subtilis. J Bacteriol 170:5662-5668

Nitschke M, Pastore GM (2004) Biosurfactant production by Bacillus subtilis using cassava-processing effluent. Appl Biochem Biot 112:163-172

Ongena M, Jacques P (2008) Bacillus lipopeptides: versatile weapons for plant disease biocontrol. Trends Microbiol 16:115-125

Oviedo C, Rodríguez J (2003) EDTA: the chelating agent under environmental scrutiny. Quím Nova 26:901-905

Peypoux F, Bonmatin J, Wallach J (1999) Recent trends in the biochemistry of surfactin. Appl Microbiol Biot 51:553-563

Qiu Y, Xiao F, Wei X, Wen Z, Chen S (2014) Improvement of lichenysin production in Bacillus licheniformis by replacement of native promoter of lichenysin biosynthesis operon and medium optimization. Appl Microbiol Biot 98:8895-8903

Sandrin C, Peypoux F, Michel G (1990) Coproduction of surfactin and iturin A, lipopeptides with surfactant and antifungal properties, by Bacillus subtilis. Biotechnol Appl Bioc 12:370-375

Sen R (1997) Response surface optimization of the critical media components for the production of surfactin. J Chem Technol Biot 68:263-270

Sen R (ed) (2010) Biosurfactants. Landes Bioscience, Austin

Sheppard JD, Mulligan CN (1987) The production of surfactin by Bacillus subtilis grown on peat hydrolysate. Appl Microbiol Biot 27:110-116

Vollenbroich D, Özel M, Vater J, Kamp RM, Pauli G (1997) Mechanism of inactivation of enveloped viruses by the biosurfactant surfactin from Bacillus subtilis. Biologicals 25:289-297

Willenbacher J, Zwick M, Mohr T, Schmid F, Syldatk C, Hausmann R (2014) Evaluation of different Bacillus strains in respect of their ability to produce surfactin in a model fermentation process with integrated foam fractionation. Appl Microbiol Biot 98:9623-9632

Yakimov MM, Timmis KN, Wray V, Fredrickson HL (1995) Characterization of a new lipopeptide surfactant produced by thermotolerant and halotolerant subsurface Bacillus licheniformis BAS50. Appl Environ Microb 61:1706-1713

Zhu Z, Zhang F, Wei Z, Ran W, Shen Q (2013) The usage of rice straw as a major substrate for the production of surfactin by Bacillus amyloliquefaciens XZ-173 in solid-state fermentation. J Environ Manag 127:96-102

\section{Submit your manuscript to a SpringerOpen ${ }^{\odot}$ journal and benefit from:}

- Convenient online submission

- Rigorous peer review

- Immediate publication on acceptance

- Open access: articles freely available online

- High visibility within the field

- Retaining the copyright to your article

Submit your next manuscript at $>$ springeropen.com 